\title{
Posterior Cruciate Ligament
}

National Cancer Institute

\section{Source}

National Cancer Institute. Posterior Cruciate Ligament. NCI Thesaurus. Code C33359.

A fibrous band extending between the posterior intercondyloid fossa of the tibia and the anterior lateral region of the medial condyle on the femur to prevent the knee from moving posteriorly. 